Publicación semestral. ISSN 2215-4906

Volumen 81 - Número 1 Julio - Diciembre 2021

\title{
Entre hilos, lienzos y memorias lacustres. Taller de textiles FARO Tláhuac
}

\author{
Between threads, canvases and lake memories. \\ FARO Tláhuac textile workshop
}

Erika Karina Jiménez Flores

DOI 10.15517/es.v81i1.47653

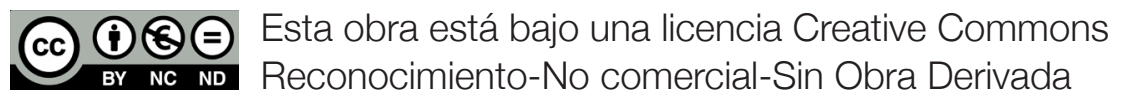


Reflexión

\title{
Entre hilos, lienzos y memorias lacustres. Taller de textiles FARO Tláhuac
}

Between threads, canvases and lake memories. FARO Tláhuac textile workshop

\author{
Erika Karina Jiménez Flores ${ }^{1}$ \\ Universidad Nacional Autónoma de México \\ Ciudad de México, México
}

Recibido: 12 de febrero de 2021

Aprobado: 24 de marzo de 2021

1 Profesora en la Facultad de Artes y Diseño de la Universidad Nacional Autónoma de México. Licenciada en Artes Visuales por la Universidad Nacional Autónoma de México. ORCID: 0000-0002-2076-8266. Correo electrónico: ekjimenez@fad.unam.mx 


\title{
¿Por qué surge esta propuesta?
}

\author{
Ma amo aca quihto: \\ -amo hueliti moihcuiloa inin tlahtolli- \\ ipampa inin tlahtolli moihcuilotoc \\ ipan amatl \\ ipan cuetlaxtli \\ ipan zoquitl \\ ipan tet/2
}

(Hernández, 2015, p. 25)

México es un país que posee una gran diversidad cultural y lingüística. Acorde a datos del Instituto Nacional de Lenguas Indígenas INALI está compuesto por 68 pueblos indígenas, los cuales han sido clasificados dentro del Catálogo de Lenguas Indígenas Nacionales ${ }^{4}$, según con el artículo 2 de la Constitución de los Estados Unidos Mexicanos:

La Nación tiene una composición pluricultural sustentada originalmente en sus pueblos indígenas que son aquellos que descienden de poblaciones que habitaban en el territorio actual del país al iniciarse la colonización y que conservan sus propias instituciones sociales, económicas, culturales y políticas, o parte de ellas (Constitución de los Estados Unidos Mexicanos [Const.], art. 2).

Derivado de este artículo constitucional, el 13 de marzo de 2003, se publicó en el Diario Oficial de la Federación la Ley General de Derechos Lingüísticos de los Pueblos Indígenas, cuyo Artículo 13, fracción IV establece "incluir en los programas de estudio de la educación básica y normal, el origen y evolución de las lenguas indígenas nacionales, así como de sus aportaciones a la cultura nacional" (Ley General de Derechos Lingüísticos de los Pueblos Indígenas, 2003). Asimismo, la fracción V indica "supervisar que en la educación pública y privada se fomente o implemente la interculturalidad, el multilingüismo

2 In Tozpaltic tlahtolli-in matlahtic tlahtolli. Libro de impresión/edición casera de Santos de la Cruz Hernández fechado y presentado en el año 2015 en la Asamblea de Migrantes Indígenas (AMI).

3 Instituto Nacional de Lenguas Indígenas. Organismo gubernamental cuyo objetivo es el fortalecimiento de la diversidad cultural y multilingüe de México.

4 https://www.inali.gob.mx/clin-inali/

ESCENA. Revista de las artes, 2021, Vol. 81, Núm. 1 (julio-diciembre), pp. 399-419 
Entre hilos, lienzos y memorias lacustres.

Reflexión

Taller de textiles FARO Tláhuac

y el respeto a la diversidad lingüística para contribuir a la preservación, estudio y desarrollo de las lenguas indígenas nacionales y su literatura" (Ley General de Derechos Lingüísticos de los Pueblos Indígenas, 2003).

Una lengua indígena u originaria brinda la posibilidad de conocer el mundo a partir de una estructura distinta a la hegemónica, misma que ha sido impuesta por la cultura colonizadora. Es importante resaltar que aunque existen estas leyes, no se hacen valer dentro de las instituciones educativas, pues el contenido académico formal en materia que concierne al fomento de la interculturalidad es escaso, debido a que los programas y planes de estudio se estructuran desde una lógica eurocentrista y colonizante. En palabras de la Maestra Hortencia Domínguez Vargas:

Intequi in huey teyacanquimeh mah motenquixti totlahtol, ipan mochi tamachtiloyan ihuan occe yeyantli. Tihnequih ma momahuizmati ihuan mah motlacaihta inin occe nemiliztli [...] Ixquichca ipan 2003 xihuitl onca ce tlanahuatilli tlen itoca "Ley General de los Derechos Lingüisticos de los Pueblos Indígenas" tlen ahmo quitlacaihta. [La obligación de los gobiernos es que incluyan las lenguas originarias en nuestra educación, en todos los niveles y espacios. Para fomentar y preservar los diferentes modos de ver el mundo..] Desde el año 2003 existe una ley que se llama "Ley General de los Derechos Lingüísticos de los Pueblos Indígenas" que no se respeta] (Garibay, 2019, 4min 24s).

Ahora bien, no es motivo de este trabajo profundizar en esta área, pero sí es relevante situar el contexto educativo actual y el por qué las instancias de educación no formal son grandes aliadas, para hacer valer las leyes que por derecho constitucional deben promoverse entre la población que habita y reside en esta geografía llamada México. Dentro de estas instancias aliadas, podemos posicionar a la Fábrica de Artes y Oficios FARO Tláhuac como pionera de este trabajo requerido por la propia comunidad y cuyo origen relata su actual líder coordinador, el artista visual Alejandro Rincón Gutiérrez:

FARO Tláhuac surgió el 26 de mayo de 2006 al suroriente de la Ciudad de México, como parte de una política pública que busca dotar de infraestructura cultural y de formación artística, así como la formación de nuevos públicos de manera gratuita, siempre con una perspectiva ambiental y de género (Facultad de Arte y Diseño de la Universidad Autónoma de México, 2021, s.p).

ESCENA. Revista de las artes, 2021, Vol. 81, Núm. 1 (julio-diciembre), pp. 399-419 
Erika Karina Jiménez Flores

Reflexión

Imagen 1. Vista de paisaje en donde se aprecia el tule (tollan)

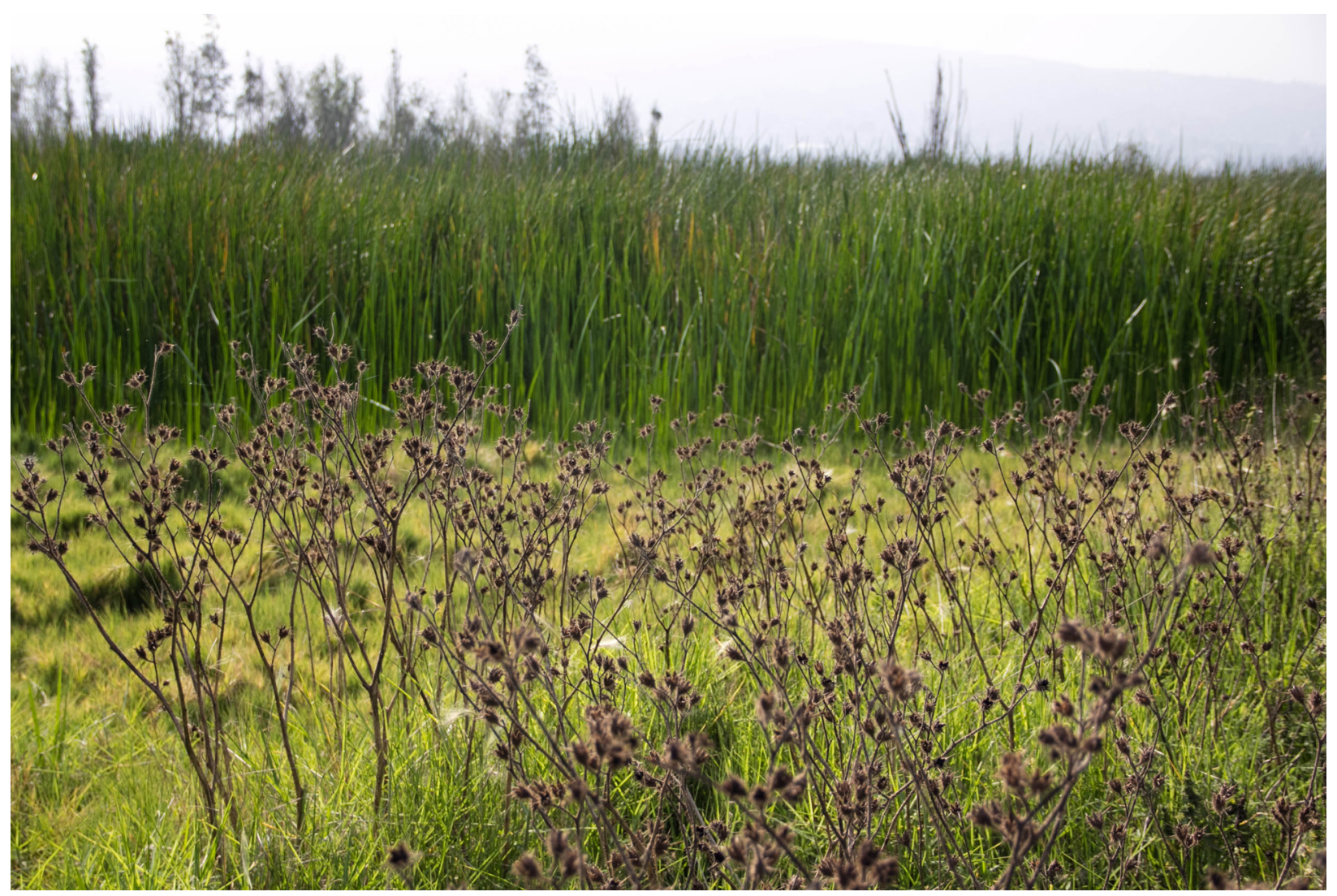

Fuente: Google Maps 
Entre hilos, lienzos y memorias lacustres.

Taller de textiles FARO Tláhuac

Imagen 2. Actual mapa de la Ciudad de México

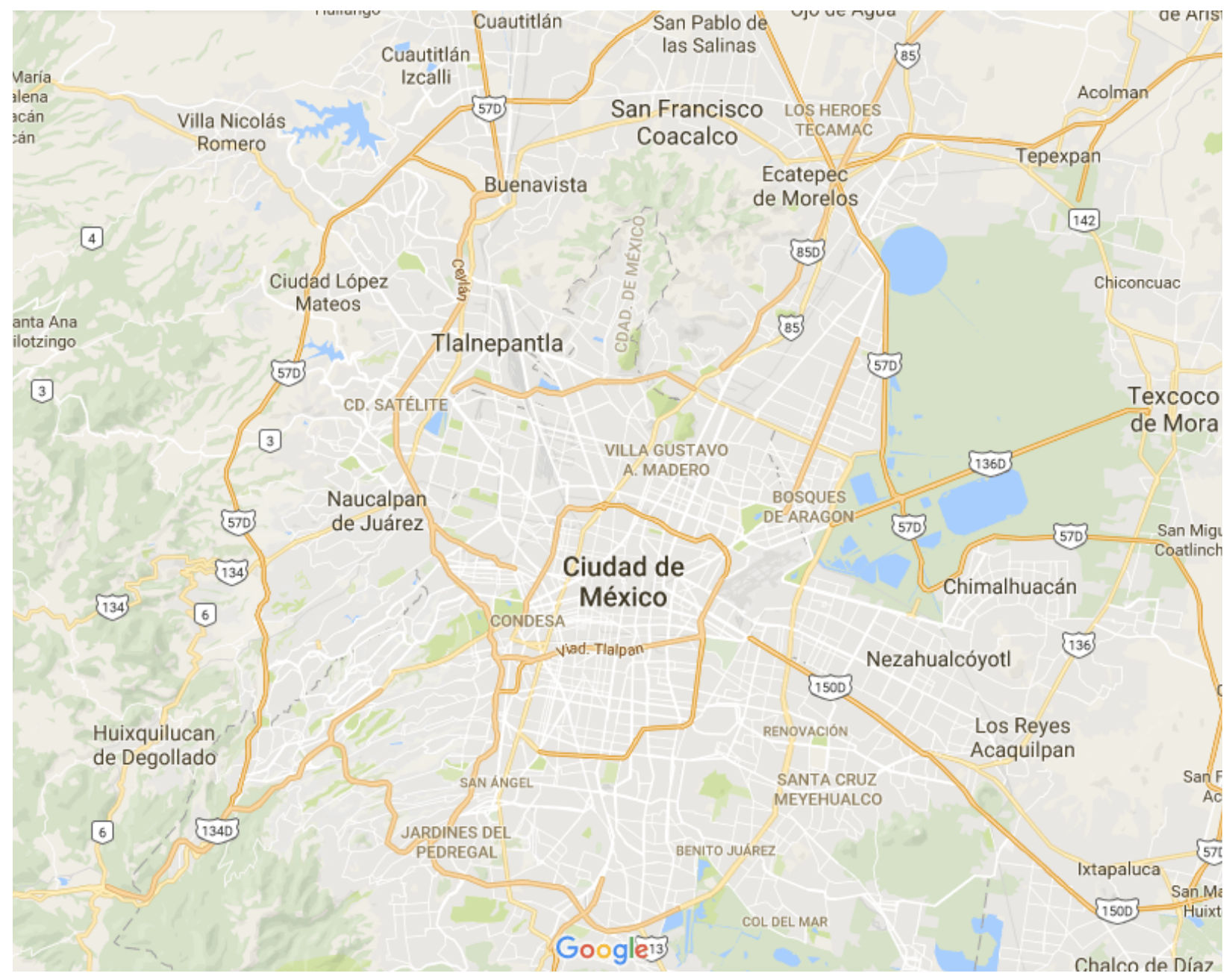

Fuente: Google Maps

ESCENA. Revista de las artes, 2021, Vol. 81, Núm. 1 (julio-diciembre), pp. 399-419 
Imagen 3. Actual mapa de ubicación de FARO Tláhuac dentro de la alcaldía

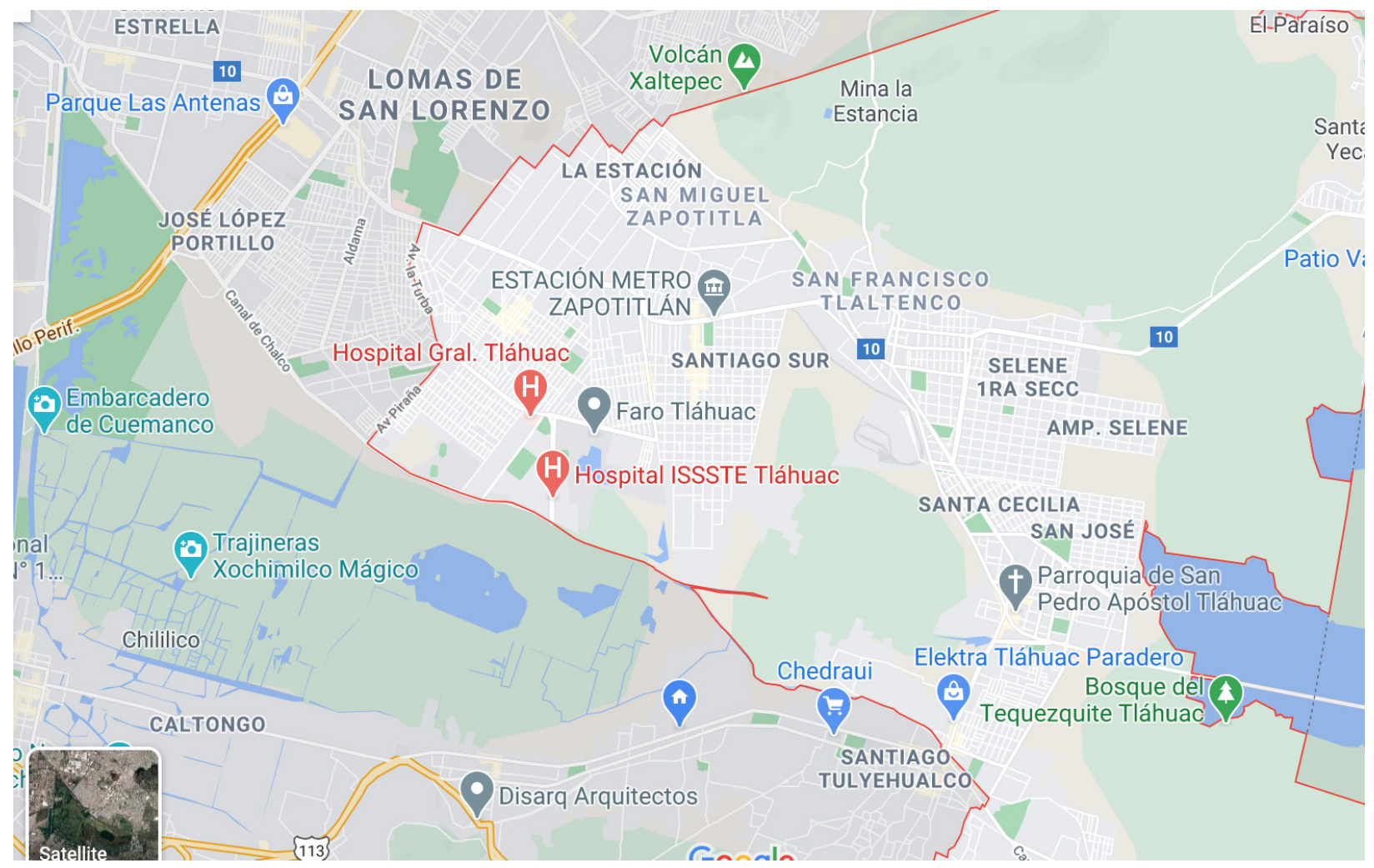

Fuente: Google Maps.

Esta visión socializadora fue el detonante que propició mi acercamiento al recinto, en una primera fase, para realizar el servicio social (2008) y, posteriormente, para proponer/ desarrollar talleres de formación textil con perspectiva intercultural, ambiental y de género (2015 a la fecha). Cabe resaltar que esta propuesta continúa en construcción y desarrollo de la mano de Alejandro Rincón Gutiérrez y la psicóloga Montserrat Landeros Soria, quien actualmente funge como Coordinadora de Talleres. 
Entre hilos, lienzos y memorias lacustres.

Reflexión

Taller de textiles FARO Tláhuac

Imagen 4. Mapa que muestra parte de los Ejidos de San Gregorio Atlapulco y San Luis Tlaxialtemalco
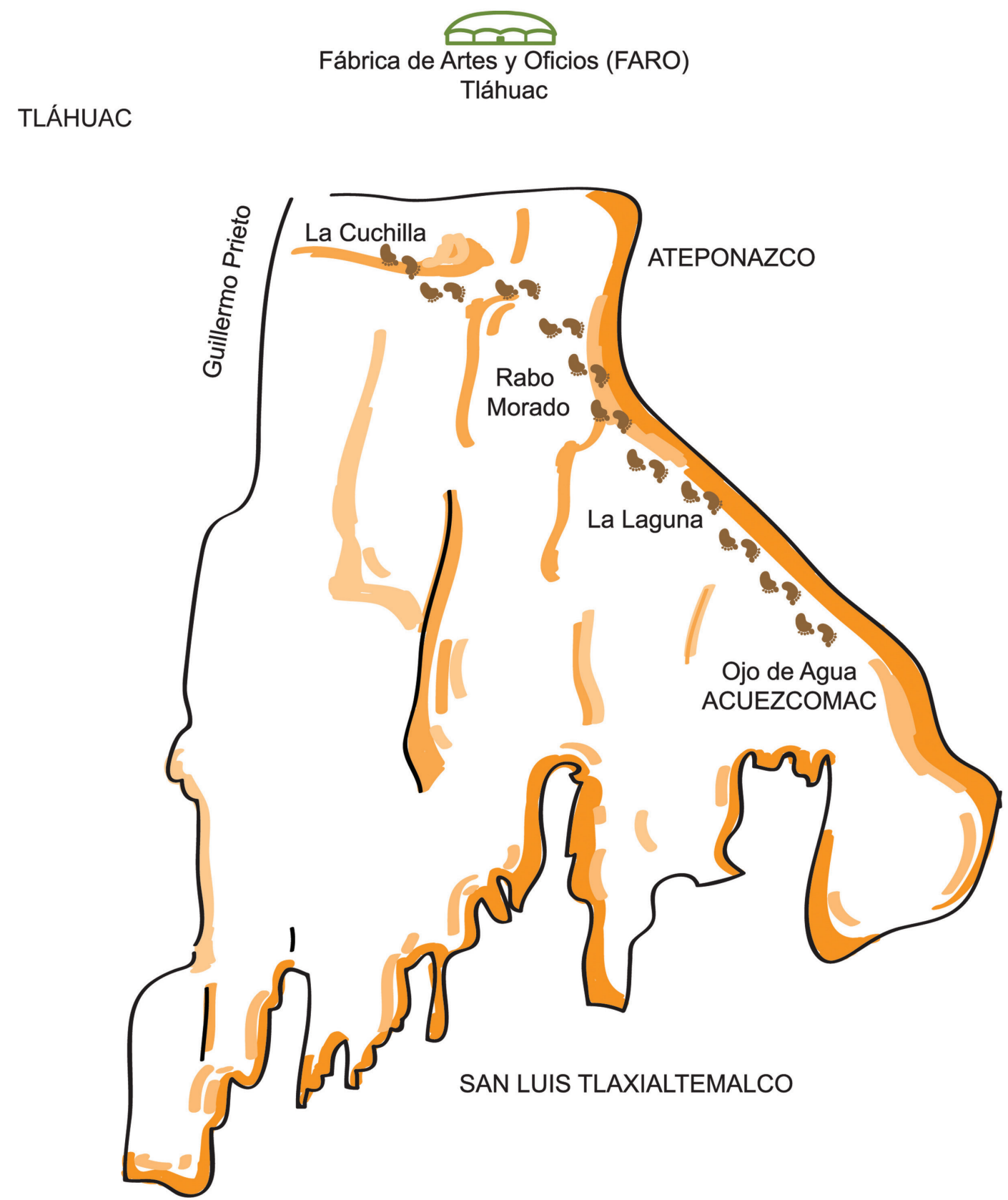

Fuente: mapa elaborado por la autora 
Es importante resaltar que la mayor parte de los escritos que refieren a la técnica de telar de cintura, la cual es motivo del taller que se analiza en este texto, se abordan a partir de una noción antropológica colonialista. En la mayoría de los casos no se conoce el proceso desde la experiencia, sino que se trata como un estudio descriptivo a partir de la observación y la explicación brindada por las y los tejedores. En este texto, no rechazamos los escritos formales, pero partimos más bien desde la experiencia viva de hacer telar de cintura y escribir desde ahí.

\section{¿Dónde se urde el tejido lacustre?}

La FARO Tláhuac se ubica en el sur oriente de la Ciudad de México en el interior del Bosque de Tláhuac, en la alcaldía Tláhuac que colinda con las alcaldías Iztapalapa, Xochimilco y el Estado de México. Desde su creación, en el año 2006, tuvo como eje la ecología y la educación ambiental, además de las artes escénicas y plásticas, entre ellas las textiles. Este interés se debe a que la región de la Ciudad de México en donde se ubica conserva algunas zonas de reserva ecológica en las que cohabitan humedales, ahuejotes (ahuexot/5), canales, chinampas (chinampan ${ }^{6}$ ), ahuehuetes (ahuehuet/ ${ }^{7}$ ), tule (tollan) y una amplia diversidad de flora y fauna.

Es precisamente esta zona de reserva ecológica la que se encuentra en medio de mi localidad de origen, San Luis Tlaxialtemalco, y la FARO Tláhuac (imagen 4). Esta es un testimonio vivo de la historia lacustre no solo de la región sino de gran parte de la Ciudad de México, la cual fue edificada sobre lagos y chinampas.

Hasta el año 1980, el espacio en donde actualmente se ubica el recinto fue territorio de cultivo, rodeado de humedales, árboles endémicos y fauna diversa. Ahora, el recinto convive con bosque, lago, parte de la reserva natural, asentamientos humanos y pequeños comercios circundantes.

${ }^{5}$ De ahora en adelante las palabras entre paréntesis y en itálicas estarán escritas en lengua nahuatl.

6 Sistema de cultivo desarrollado por los primeros pobladores de la región lacustre, consiste en apilar ramas y extraer lodo del fondo del lago para conformar un terreno sobre el agua, se rodea por ahuejotes para fijarlo. Literalmente es tierra de cultivo flotante.

7 En lengua nahuatl se puede traducir como "viejo del agua" pues tiene la particularidad de ser muy longevo y para vivir debe estar sobre una superficie acuosa continua.

ESCENA. Revista de las artes, 2021, Vol. 81, Núm. 1 (julio-diciembre), pp. 399-419 
Entre hilos, lienzos y memorias lacustres.

Reflexión

Taller de textiles FARO Tláhuac

Imagen 5. Madre instruyendo a su hija en la práctica de confección de textiles en telar de cintura

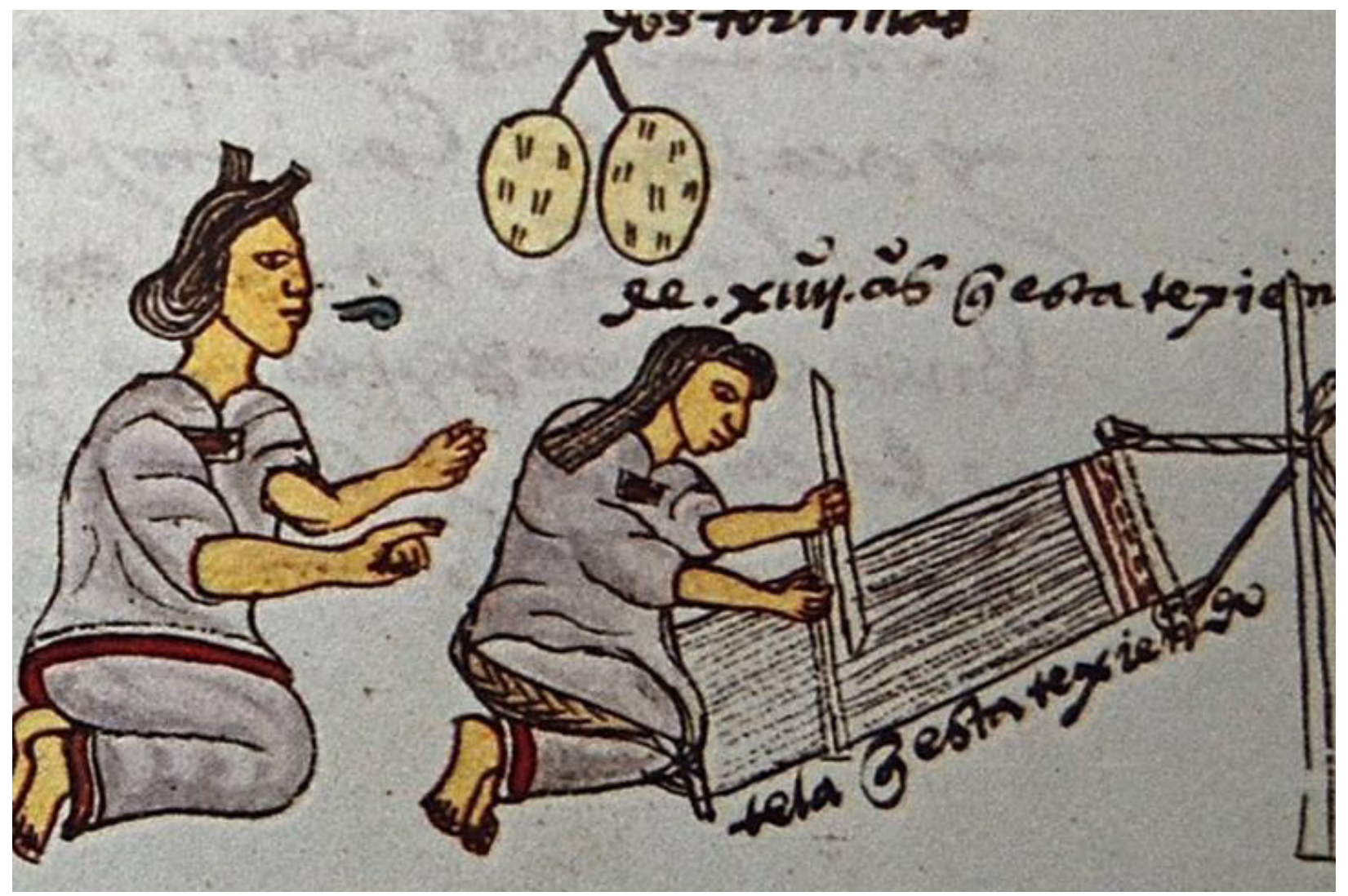

Fuente: Google Maps.

\section{Memorias tejidas por niños y niñas de Tláhuac}

En el año 2015, inicia una primera fase de esta propuesta con un taller telar de cintura para niños de entre 6 y 9 años que tuvo una duración de tres meses. Esta técnica data de la época previa a la llegada de los españoles y se enseñaba sobre todo al interior del seno materno a las niñas generalmente. Sahagún refiere:

comienza luego a hacer lo que es tu oficio, o hacer cacao, o moles maíz, o a hilar o a tejer... y si por ventura vinieres a necesidad de pobres, mira, aprende muy bien y con gran advertencia el oficio de las mujeres, que es hilar y tejer, abre bien los ojos para ver como hacen delicada manera de tejer y de labrar, y de hacer las pinturas de las telas, y como ponen los colores y como juntan los unos con los otros 
para que digan bien, las que son señoras y hábiles en este arte; aprende bien como se urde la tela y como se ponen los lienzos en la tela, como se ponen las cañas entre la una y la otra, para que se pase por en medio la lanzadera (Sahagún, citado en De Rojas, 1986, p. 139).

En la actualidad, en diversas localidades del país, esta técnica sigue presente y se explica en sus propios términos, desde la experiencia viva del hacer, lo que contrasta con una descripción ajena a la labor artesana. Tal es el caso de la maestra tejedora Leocadia Cruz Gómez "Tía Cayita" originaria de Cosoleacaque, Veracruz, quien en entrevista comparte:

Mi mamá hacía puras fajas y refajos como antes las antiguas. Ella, mi mamá, sembraba algodón. Ellas no podían, como nosotras ahorita, ir a la tienda a comprar hilo. Ellas sembraban algodón, lo secaban y hacían hilo para hacer tela... Como yo era chica me daba cuenta de lo que hacía mi mamá. Y me gustó también... Yo aprendí a tejer a la edad de ocho años, chica. Me mandaban a plantar algodón. Decían: ese trabajo así se hace y así se hace la tela. El algodón se siembra en setiembre. Sembrábamos como también se siembra la milpa, dos granitos. A los tres meses ya florean y cuando ya estaba grande el algodoncito se limpiaba, bien limpio. Y a los cuatro meses se va a cortar. Antes el hilo se hacía a mano, le sacaban toda la semillita al algodón y, luego, bien machacadito lo hilaban. En una tarde ellos sacaban 20 bolas de hilo, con eso llenaban dos malacates (Paul, 2006, párr. 8).

"Tía Cayita" es toda una inspiración. Aunque ella aprendió de su madre, es cierto que tiene la preocupación por que se siga fomentando la enseñanza de esta técnica tan antigua entre las generaciones más jóvenes, por lo que instaló un taller en su casa. Por esta importante labor, fue distinguida con el Premio Nacional de Ciencias y Artes 2006, en la categoría de Artes y Tradiciones Populares. Con la obtención del premio, construyó el Centro Cultural Nigan Tonogue, en donde además de la técnica de telar de cintura se fomentan otras disciplinas como la música y el zapateado.

En la región sur-oriente de la Ciudad de México, se conserva la técnica de telar de cintura en el poblado de Santa Ana Tlacotenco, ubicado en la alcaldía de Milpa Alta, colindante con el Estado de México y Morelos. En esa localidad existió una preocupación porque las generaciones más jóvenes ya no querían aprender esta técnica, pues el cambio de vida y la creciente urbanización motivaron el aprendizaje de otros oficios y 
Entre hilos, lienzos y memorias lacustres.

Reflexión

Taller de textiles FARO Tláhuac

profesiones. Sin embargo, han florecido instructores y guías ${ }^{8}$ de nueva generación que han fomentado este aprendizaje en la región.

Estos antecedentes, sin duda, motivaron mi colaboración con Dolores Juárez Jiménez ${ }^{9}$, quien posee una admirable maestría en la ejecución de la técnica y quien claramente aportó una línea central para el cuidado y desarrollo de este saber. Aun en condiciones adversas, se sumó al taller, pues su conocimiento es crucial para el fomento de esta técnica en la región lacustre. En este sentido, es importante declarar que este taller se ha desarrollado desde la colaboración horizontal gracias a las facilidades otorgadas por el equipo operativo de la FARO Tláhuac.

La maestra Tere Garduño ${ }^{10}$ dice que debemos "tener derecho a construir pedagogía" (Gaceta REMFA, 2019, p. 4). Tanto las compañeras instructoras como las tejedoras originarias están ejerciendo ese derecho, no esperan a ser validadas por un sistema hegemónico que está regido por una única realidad de condiciones educativas. Estas pedagogías construidas responden a las necesidades geográficas, culturales y tradicionales de la población a la que están dirigidas; consideran que las niñas y los niños que habitan en estas zonas viven las realidades de lo lacustre, de sus paisajes y cuidados. Así, se fomenta la importancia de lo ecológico y lo natural, se nombran como deben nombrarse, en lengua nahuatl porque así han sido enseñadas y aprendidas; se visibiliza el oficio como saberes válidos y dignos por sí mismos de apropiación a sus vidas y a lo que los rodea. Como anteriormente mencionaba "Tía Cayita", se entiende que estas pedagogías buscan el cuidado, acompañamiento y trascendencia de estas prácticas originarias por ser parte de nuestras vidas.

Además, la pedagogía que se construye a partir de los saberes compartidos en estos talleres no se refiere a una pedagogía que se encuentra en los libros, sino a una que se está construyendo al andar de ella. Por lo tanto, es:

8 Tal es el caso de Iris Lozano Salman y Daniela Rodríguez Ibarra. Maestras jóvenes originarias de Milpa Alta y San Pedro Atocpan respectivamente, fomentan la técnica en recintos culturales de la Alcaldía Milpa Alta.

9 Tejedora originaria de San Cristóbal Xallan, Xochimilco, Ciudad de México.

${ }^{10}$ Dra. Teresita Garduño, fundadora de la Escuela Activa Paidós, directora y maestra de la misma desde hace 44 años. Psicóloga educativa, maestra en Ciencias y doctora en letras y psicopedagogía. Practicante de las Técnicas Freinet.

ESCENA. Revista de las artes, 2021, Vol. 81, Núm. 1 (julio-diciembre), pp. 399-419 
Imagen 6. Material didáctico "Ihquitiloni".(Las partes del telar de cintura en lengua náhuatl)

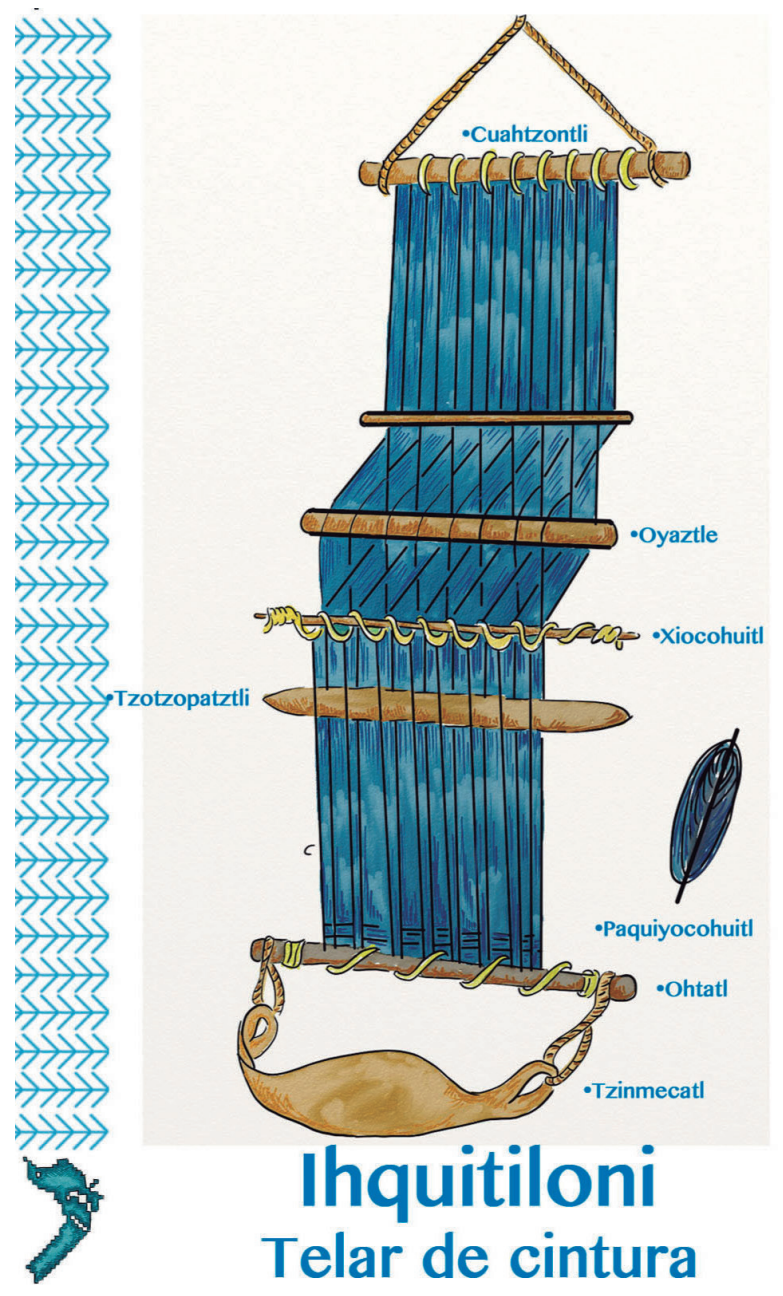

Fuente: dibujado por la autora la pedagogía viva que se construye y construimos en el camino de luchar y sembrar, cultivar y sostener los mundos-otros y modos-otros, que va marcando y significando los entretejeres de lo pedagógico y decolonial... Las prácticas accionales, las apuestas praxísticas-políticas y los procesos metodológicos y organizativos que empleamos e inventamos tanto para luchar en contra del proyecto guerra-muerte como para crear, posibilitar y afirmar la vida fuera de la lógica-estructura capitalista-patriarcal-moderno/colonial imperante (Walsh, 2017, pp. 42-43).

Así, en FARO Tláhuac el modelo pedagógico del taller tuvo 3 fases, mismas que describiré brevemente:

\section{Fase 1. Módulo teórico}

Esta fase trató sobre historia del telar y aprendizaje de las partes del telar en lengua nahuatl, para lo cual se elaboró material didáctico (imagen 6) en donde, de forma esquemática, se nombra cada una de las partes del telar en lengua nahuatl. Tras el aprendizaje de las partes que componen el telar, todos los niños y niñas elaboraron un esquema personal (imagen 7). 


\section{Fase 2. Urdido}

Tlatehteca, en lengua náhuatl, se refiere al proceso que consiste en entrecruzar los hilos de urdimbre sobre estacas que se entierran en la tierra para preparar el soporte del tejido. Este proceso implica el conteo preciso y cuidadoso de los cruzamientos entre cada una de las estacas. Esto se lleva a cabo mediante la observación del hacer, en donde las talleristas rea-

Imagen 6. Dibujo "Ihquitiloni". (Las partes del telar de cintura en lengua náhuatl dibujadas por Astrid, en el taller)

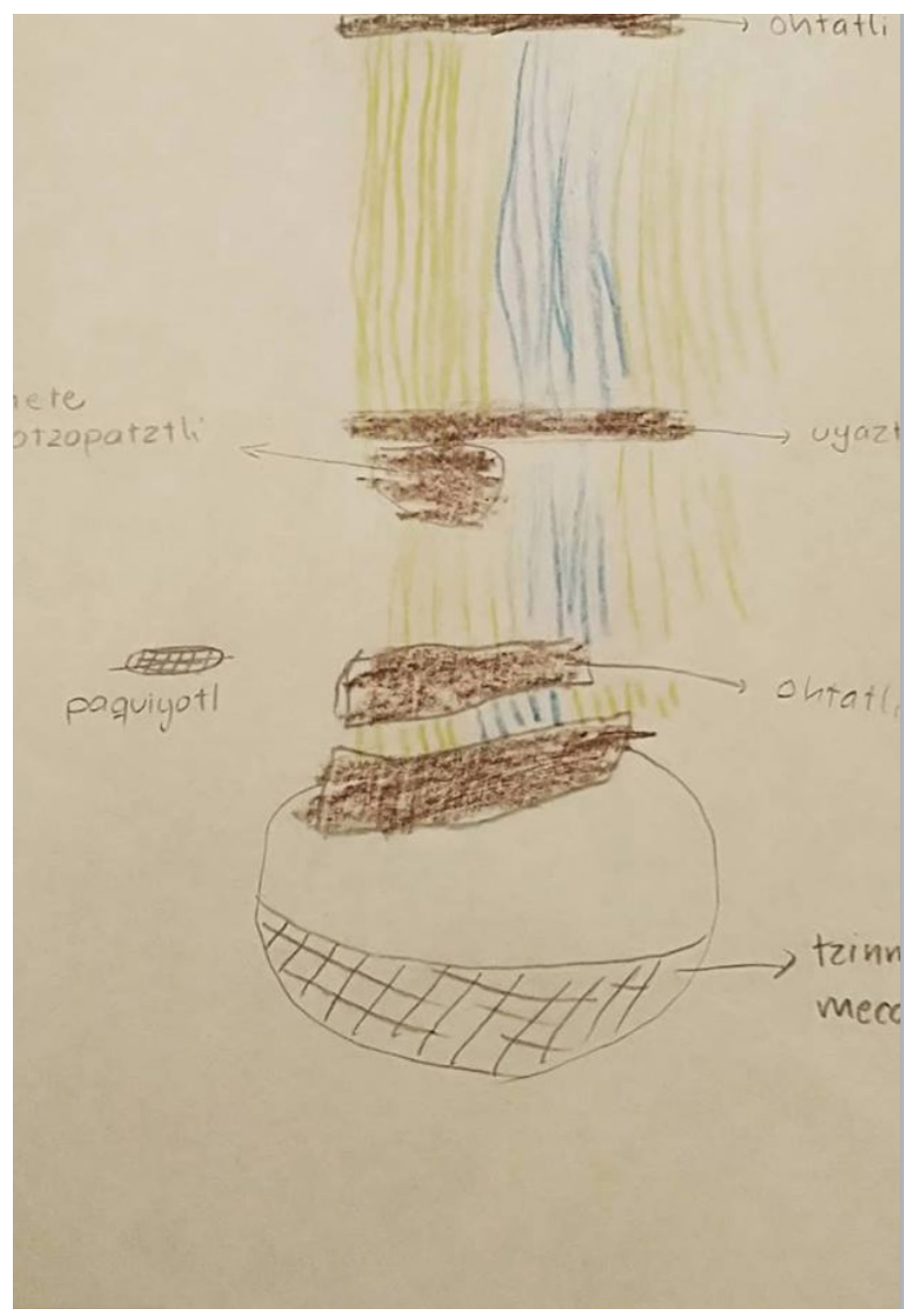

Fuente: archivo personal de la autora. lizan tres cruzamientos que se asemejan el trazo de un "ocho" en toda la urdimbre; para esta acción la concentración y la paciencia son de vital importancia. La dinámica de urdido se realizó en pequeños equipos de trabajo; mientras uno de los niños realizaba el urdido el otro observaba el proceso, así ambos podían estar al pendiente de posibles errores en el proceso.

\section{Fase 3. Montado y tejido}

En esta fase se transfiere la urdimbre al telar, se preparan los hilos y el jiyote (xiotl) ${ }^{11}$, que es una pieza clave para que se genere el tejido. Posteriormente, se va alimentando el tejido con la trama o (paquiyotl), este proceso requiere una disposición específica del cuerpo para que el tejido vaya quedando uniforme. Con este ejercicio, los niños practican la me-

\footnotetext{
${ }^{11}$ Pieza que sirve para levantar los hilos pares y crear un "calado" o espacio entre ambos juegos de hilos al que se inserta la trama. (Vela et.al, 2014, pp. 80-81).
} 
Imagen 8. Samuel de 5 años urdiendo un morral, para guardar su comida y llevarla a la primaria.

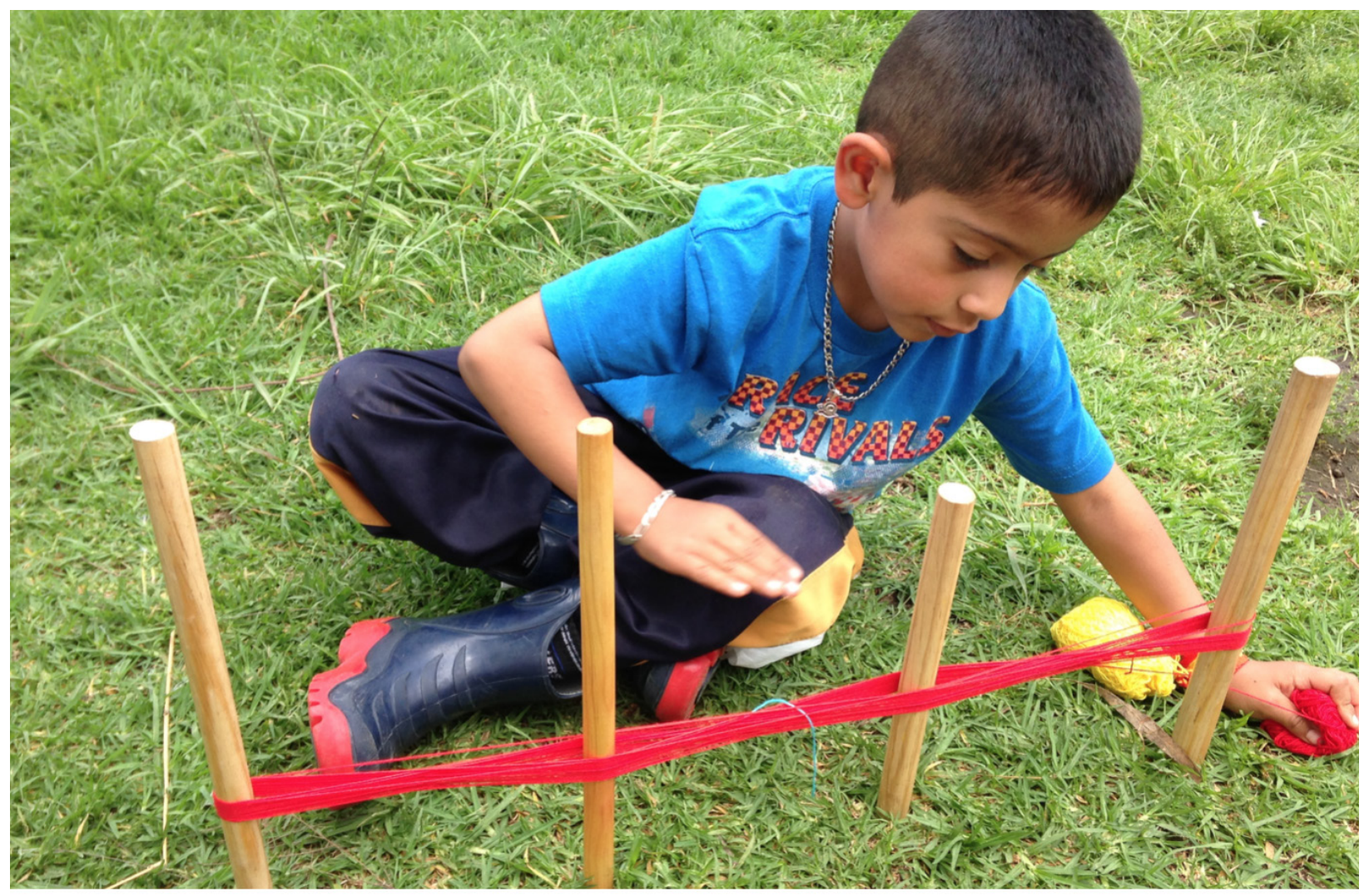

Fuente: archivo personal de la autora

moria corporal y sensitiva, como parte de un proceso cognitivo integral, que no solo apela a la instrucción verbal, sino a la conexión corporal y con los materiales ${ }^{12}$. En ese sentido, la práctica textil tiene varias metáforas relacionadas a la cultura y pensamiento previos a la llegada de los españoles, pues el lienzo emerge del vientre de la mujer y va creciendo a

\footnotetext{
${ }^{12}$ Según las Técnicas Freinet, este cuidado por la conexión corporal con los materiales está íntimamente relacionado al Tanteo Experimental y el Método Natural que refieren a la libertad y capacidad del niño por conocer los procesos por sí mismo, aportando a su propio aprendizaje significativo y que, en el caso del taller descrito, está inserto en su vida cotidiana. Curso taller en línea "Técnicas Freinet con Orientación a la Alfabetización inicial”, 2020, realizado por el Grupo MMEM (Movimiento Mexicano para la Educación Moderna).
} 
medida que la tejedora "lo alimenta"; para los antiguos el telar está vivo, no es inerte. E telar siente, va guardando nuestros pensamientos y nuestras emociones. Acorde a Denise Arnold y Elvira Espejo:

En los procesos de elaboración textil... el urdido y tejido [son] dos momentos determinantes y estrechamente interrelacionados; en primer lugar, porque las técnicas del urdido generan la estructura del textil y, en segundo lugar, porque las técnicas posteriores de selección y conteo de los hilos de urdimbre derivan de las posibilidades desplegadas por esta estructura textil. Solo al cumplir estos dos procesos íntimamente ligados se puede pasar a la elaboración de los motivos, diseños o figuras textiles, cuyas posibilidades de expresión también dependen de las estructuras y técnicas textiles en vías de elaboración (Arnold \& Espejo, 2019, p. 6).

Por su parte Soledad Hoces y Paulina Brugnoli apuntan que: "en los Andes los textiles son concebidos como seres vivos, por esa razón desde el momento inicial, sus bordes son parte fundamental de la construcción. El objeto no debe presentar cortes y "nace" como un cuerpo en el telar" (Hoces \& Brugnoli, 2006, p14).

\section{Fase 4. Desmontado y armado de la prenda}

Una vez concluido el proceso de tejido, se procede al desmontado de la prenda. Esto se realiza de manera cuidadosa, sacando de los ohtat/13 los hilos uno por uno; una vez que el lienzo está fuera se procede a quitar el xiotl de igual manera, paciente y delicada.

Imagen 9. Proceso de tejido

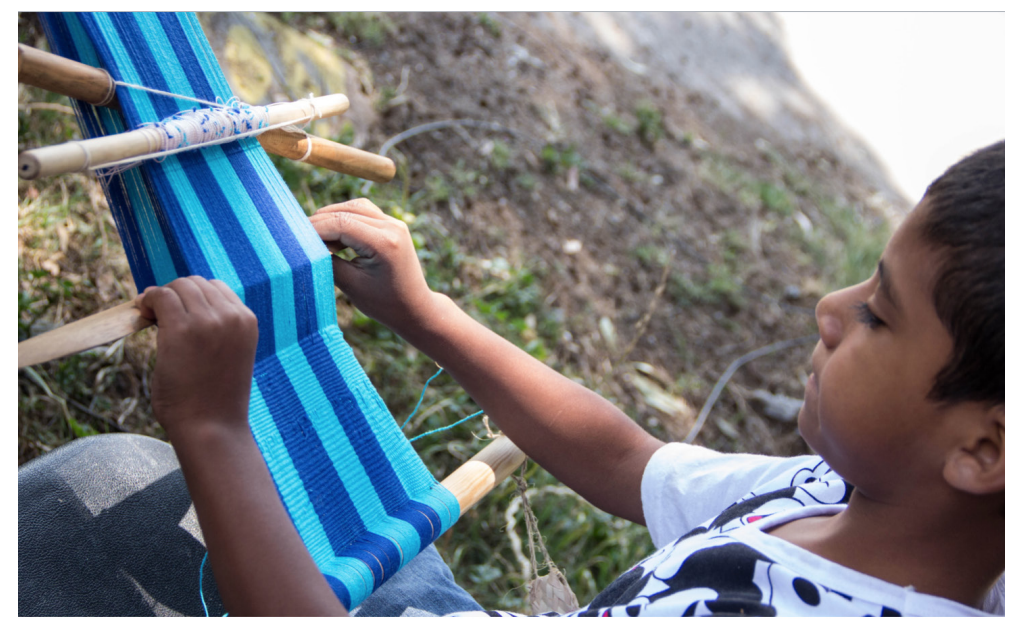

Fuente: archivo personal de la autora

\footnotetext{
${ }^{13}$ Significa un rumbo o camino a seguir recto. Un ohtatl (otate) se coloca en la cintura de la tejedora, lo que permite sujetar un extremo del telar, pero también que la tejedora mantenga debidamente tensa la urdimbre; el otro extremo se mantiene por medio de un mecatl (mecate) amarrado a cualquier punto fijo, generalmente en un árbol. Como se muestra en la imagen 10.
} 
Imagen 10. Proceso de tejido

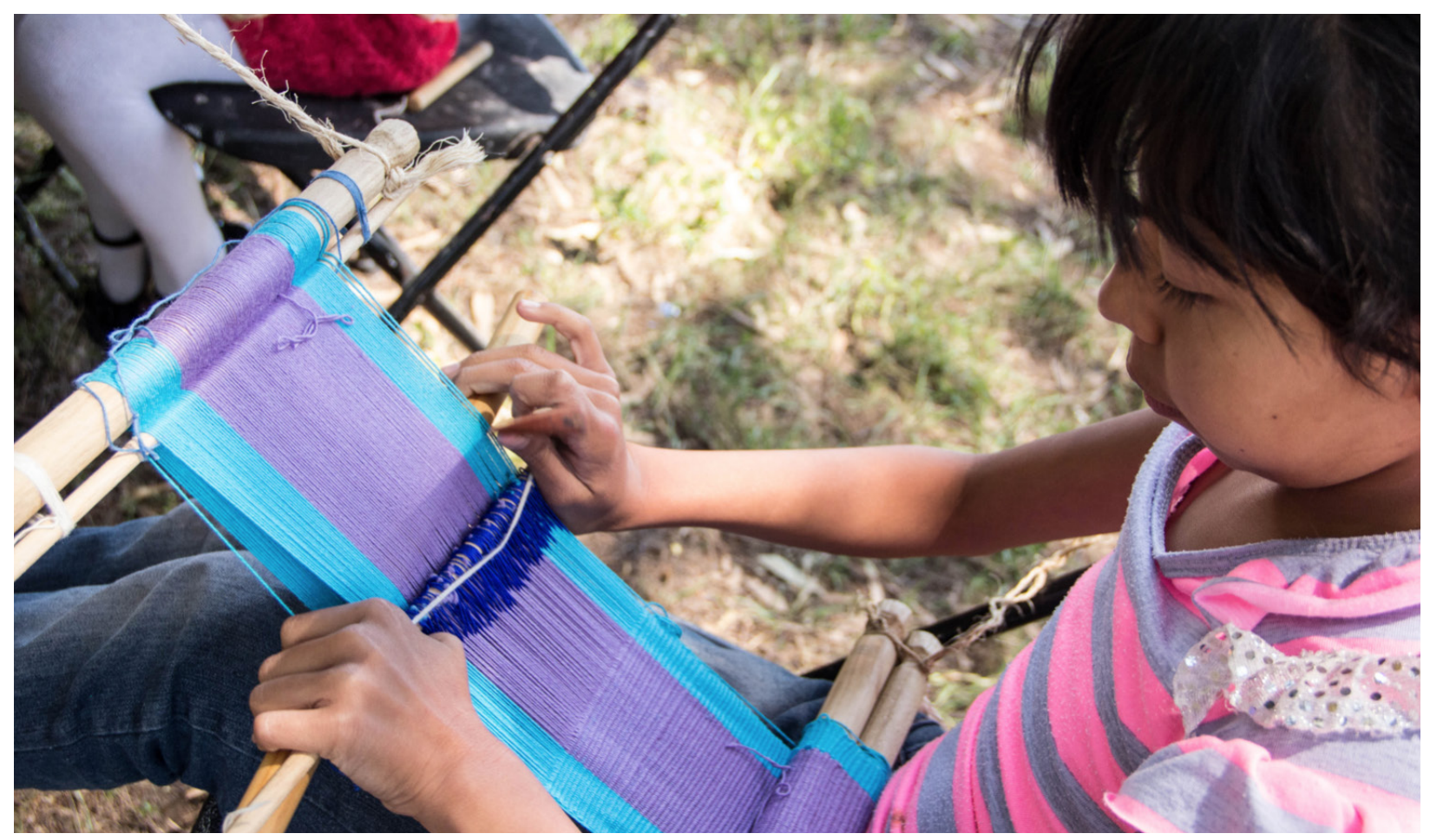

Fuente: archivo personal de la autora

La confección del morral fue sencilla. Se sabe que en la antigüedad la mayoría de las prendas eran concebidas a partir de rombos y cuadrados. En este caso en particular se tejió un lienzo de aproximadamente $55 \mathrm{~cm} \times 130 \mathrm{~cm}$, por lo cual se procedió a doblarlo de la forma en la que se representa en la imagen 11.

Una vez concluido el proceso de confección, se procedió a elaborar la pequeña cinta a la medida de cada uno de los infantes. Al finalizar este paso, se generó una pequeña asamblea para conocer sus opiniones acerca del taller. La mayoría de ellos refirieron que aunque fue un proceso complicado se divirtieron; otros comentaron que les gustaría continuar aprendiendo para hacer prendas más grandes. También refirieron que les hubiera gustado aprenderlo antes. En general, la sensación de haber producido algo con su esfuerzo y dedicación les pareció gratificante. 
Entre hilos, lienzos y memorias lacustres.

Imagen 11. Esquema de confección

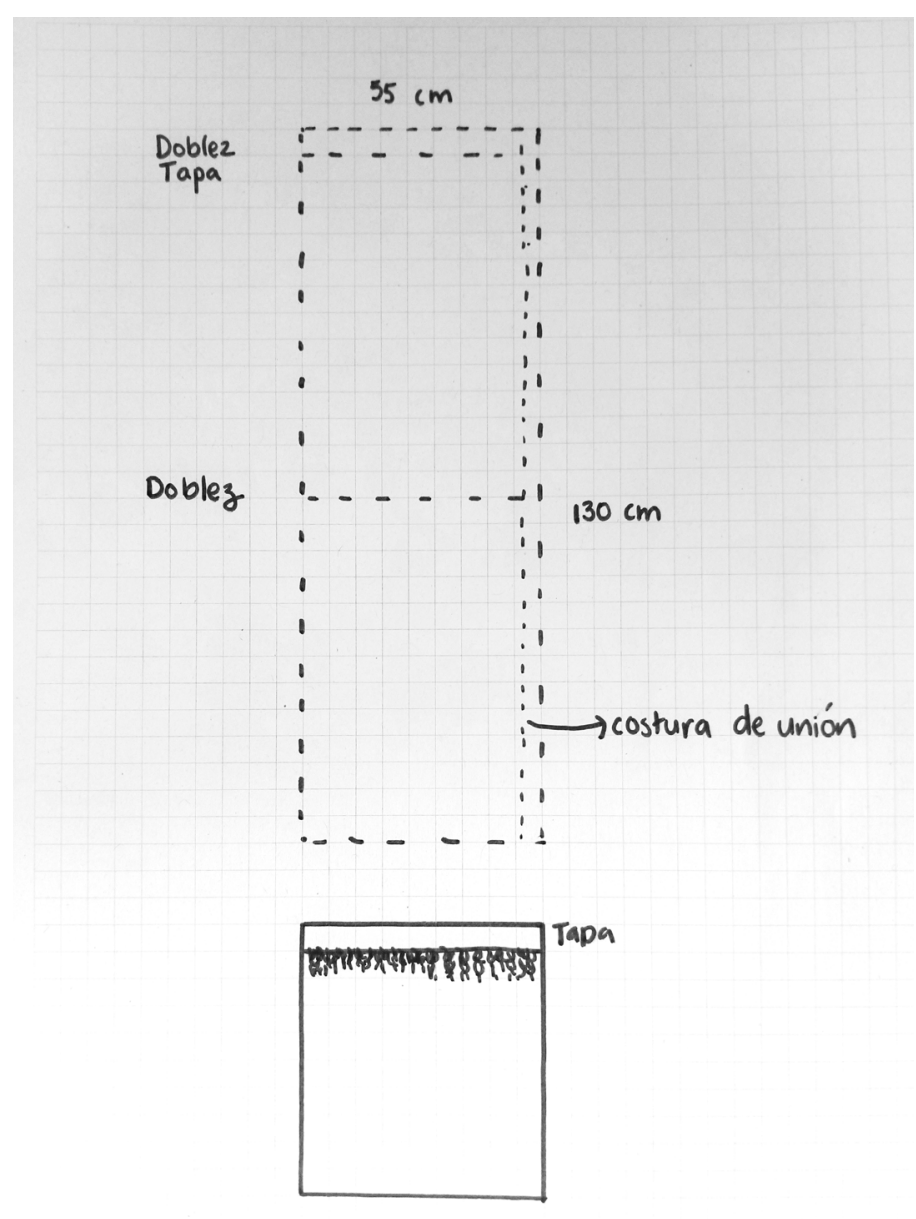

Fuente: dibujado por la autora
En este sentido, me interesa recalcar el hecho que los textiles formaban parte de la vida, desde el momento del nacimiento. Irmgard Weitlaner Johnson ${ }^{14}$ hace referencia al tiempo posterior del nacimiento de una niña

se le traían utensilios para hilar y tejer y simbólicamente se le instruía en su uso. Cuando una mujer se sentía próxima a la muerte, frecuentemente quemaba todos los implementos de su trabajo cotidiano para que la esperaran en el mundo del más allá (Weitlaner Johnson, p. 8).

El estilo de vida impuesto por la colonización ha mermado la transmisión de este tipo de saberes al interior del seno materno. Esta propuesta solo es un pequeño esfuerzo desde un lugar específico, pero como ya lo ha mencionado Victoria Novelo (2015) "las producciones artísticas indígenas no han tenido un cabal reconocimiento como parte de una cultura propia, como producto de destrezas y talentos especiales y, mucho menos, como parte de la vida total" (Novelo, p. 175). De ese modo, estos saberes han sido sistemáticamente desplazados e infravalorados. Por ello, es cierto que hacen falta esfuerzos que se lleven a cabo de manera continua y dentro de la educación formal, como el siguiente ejemplo:

\footnotetext{
${ }^{14}$ Antropóloga y maestra en arte por la Universidad de Berkeley. Investigadora y estudiosa de los textiles indígenas mexicanos, en especial de los tejidos en telar de cintura
} 
la educación primaria, en los pocos minutos que dedica a la educación artística y tecnológica, bien podría empezar a dedicar horas al estudio de procesos de trabajo, de patrones estéticos, de producciones locales y regionales; a la investigación y experimentación que despierte el interés y el gusto por saber lo que somos y hemos sido (Novelo, 2002, p. 176).

Imagen 11. Victoria con su morral terminado

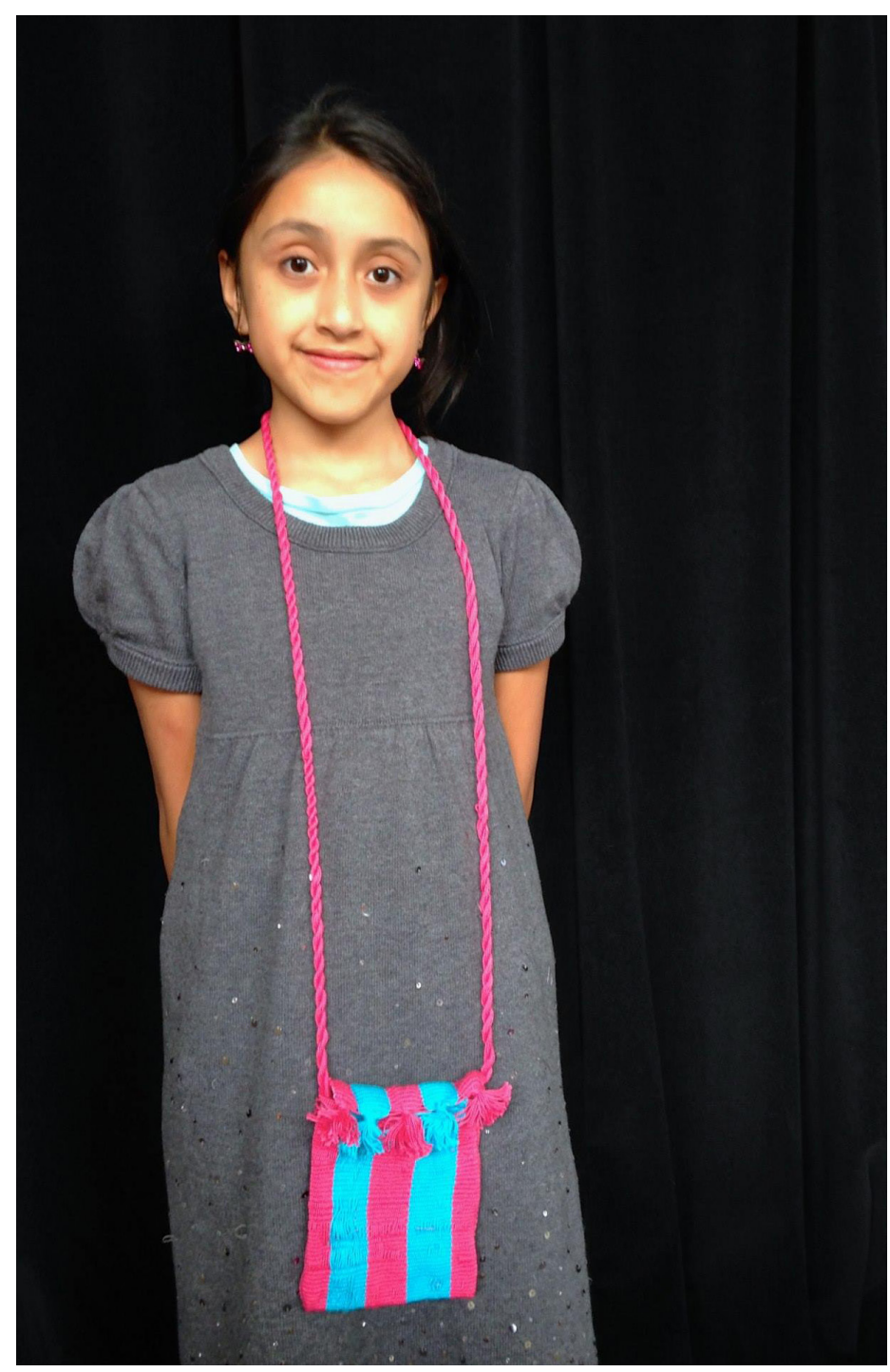

Fuente: archivo personal de la autora

\section{Para finalizar}

El proceso pedagógico de este taller apela al fortalecimiento del conocimiento corporal, sensitivo y táctil, ya que los hilos se vuelven una extensión del cuerpo mismo, pero también de las emociones. De esta manera, cada tejido resultante es un diálogo continuo del cuerpo con los hilos; la introspección se da a partir de la concentración que requiere cada uno de los pasos. Es posible brindar estas herramientas a las niñas y a los niños de Tláhuac para fortalecer el aprendizaje desde lo que hasta ahora ha sido considerado como las otras metodologías y prácticas, pero que, en realidad, es un conocimiento que floreció en este territorio, mismo que ha sido negado sistemáticamente por el Estado y por las Instituciones Educativas formales.

Por lo tanto, este pequeño taller es un acto de justicia para que los niños y niñas de Tláhuac tengan acceso a lo que por ley les corres- 
Entre hilos, lienzos y memorias lacustres.

Reflexión

Taller de textiles FARO Tláhuac

ponde aprender, valorar y preservar. Es verdad que solo es el inicio de un proceso de largo aliento para que se puedan establecer criterios de análisis más profundos. Sin embargo, este esfuerzo colectivo da cuenta de la ardua labor que sigue pendiente por activarse y reconocerse desde los espacios de educación formal, pues la interculturalidad sigue haciendo un llamado a las y los formadores para incluir este tipo de contenidos y así dar cuenta de la complejidad de las técnicas, mismas que fortalecen aspectos cognitivos, corporales, matemáticos y sensoriales.

Se requiere también que el Estado se comprometa a brindar un seguimiento y acompañamiento adecuados en la implementación de estos programas. Es importante que se reconozca la labor formativa desde la interculturalidad y se gestionen apoyos dignos para cada uno de los promotores, porque sin ellos estas historias no se estarían relatando pues la memoria ya habría fenecido.

\section{Referencias}

Arnold, D. Y. \& Espejo, E. (2019). Ciencia de tejer en los Andes: Estructura y técnicas de faz de urdimbre. La Paz, Bolivia: Garza Azul.

Constitución de los Estados Unidos Mexicanos [Const.]. 5 de febrero de 1917 (Estados Unidos Mexicanos).

De la Cruz Hernández, S. (2015). In Tozpaltic tlahtolli-in matlahtic tlahtolli. Ciudad de México: edición casera.

De Rojas, J. (1986). México-Tenochtitlan, economía y sociedad en el siglo XVI. Ciudad de México: Fondo de Cultura Económica.

Facultad de Artes y Diseño de la Universidad Nacional Autónoma de México. (2021). Segunda Bienal de Arte y Diseño UNAM 2020: Pedir Lo Imposible. (Trabajo inédito).

Gaceta REMFA. (11 de julio de 2019). La gaceta del Encuentro de Educación Emancipadora de América,2. Recuperado de https://drive.google.com/file/d/1aCLMoDImn-H76Onon5BsfytnT-sHkd46

Garibay, A. (8 de agosto de 2019). Xochitlahtolli (Palabra florida). [Video de Youtube]. Recuperado de https://youtu.be/wgRPHruRxqg.

ESCENA. Revista de las artes, 2021, Vol. 81, Núm. 1 (julio-diciembre), pp. 399-419 
Hoces, S. \& Brugnoli, P. (2006). Manual de técnicas textiles andinas: terminaciones. Santiago, Chile: Museo chileno de arte precolombino.

Ley General de Derechos Lingüísticos de los Pueblos Indígenas, Diario Oficial de la Federación, Ciudad de México, 13 de marzo de 2003.

Novelo, V. (2002). Ser indio, artista y artesano en México. Espiral, Estudios sobre estado y Sociedad, 9(25), 165-178.

Paul, C. (8 de noviembre de 2006). Tenaz resistencia de Leocadia Cruz por preservar la técnica del telar de cintura. La Jornada. Recuperado de https://www.jornada.com. mx/2006/11/08/index. php?section=cultura\&article=a06n1cul

Vela, E., Noriega, M., Díaz, D., Estrada, M., Cabezas, J. \& Ramírez, R. (2014). El telar. Arqueología Mexicana, 55, 80-81.

Walsh, C. (Ed.) (2017). Pedagogías decoloniales. Prácticas insurgentes de resistir, (re)existir y (re)vivir (Tomo II). Quito, Ecuador: Ediciones Abya-Yala.

Weitlaner, I. (2005). El vestido prehispánico del México Antiguo. Arqueología mexicana, 19, 8-9. 